\title{
The Organizational Context, Job Embeddedness, And Effectiveness Of Managing Knowledge Work Teams
}

Jau-Rong Chen, Mingchi University of Technology, Taiwan

Tzu-Chuan Chou, National Taiwan University of Science and Technology, Taiwan

Te-Wei Wang, University of Illinois at Springfield, USA

\begin{abstract}
The relationships between organizational context, job embeddedness, and knowledge work team effectiveness are examined in this paper. We proposed a research model and tested the model empirically based on a sample of 144 enterprises from the Taiwanese Information Service Industry. The results show that open-mindedness and organizational commitment are positively related to job embeddedness. Job embeddedness also has strong relationship with knowledge work team effectiveness. However, the link between job autonomy and job embeddedness is not significant.
\end{abstract}

Keyword: knowledge work team (KWT), autonomy, job embeddedness, organizational context

\section{INTRODUCTION}

9 ffective management of knowledge workers is crucial in sustaining an organization's competitive advantage (Kubo and Saka, 2002). What is the best way to effectively manage knowledge workers? The answer may be hidden in the research of project team management. In 1997, two management consultants, Kimball Fisher and Mareen Duncan Fisher published a book with the title "The Distributed Mind: Achieving High Performance through the Collective Intelligence of Knowledge Work Team" (Fisher \& Fisher, 1997). In this book, they asked the readers to accept that knowledge work takes places in a team-based environment. This assumption was soon challenged by the academic community (Safferstone, 1998). After years of discussion, few would question the importance of team management in the context of managing knowledge workers today. In the literature, several researchers advocate that understanding the dynamic of how knowledge workers collaborate is an important research topic (e.g., Janz et al., 1997; Burch and Anderson, 2004, Dineen, 2005; West and Markiewicz, 2004). Many believe that proper team management have synergetic effects a across different parts within an organization (Trent, 2003; Erdem and Ozen, 2003).

Among factors investigated by researchers, organizational context and corporate culture are of particularly interests to us. Knowledge worker management, knowledge work team management, and organization context/culture seem to interweave tightly together and have profound impacts on sustainable competitiveness. For example, to ensure it only hire and promote the smartest and like-minded talents, Microsoft has the tradition of using unconventional puzzles, games and practical jokes to test its potential employees. Microsoft also ask both its top executives and employees to stay low profile in business traveling while give them a lot of freedom inside the organization. All these are to maintain an organization norm so knowledge workers can "stay hungry" (Poundstone, 2004 p. 55). Another successful company, Google, is also proud of building a friendly environment for its talented workers. Bala Iyer and Thomas H. Davenport, in their recent Harvard Business Review Paper, attribute Google's success to "well-considered organizational and cultural strategy" (Iyer and Davenport, 2008). This well considered organizational and cultural strategy makes employee feel embedded in their working environment. Thereby, Google's knowledge workers tend to be more creative and productive. 
In this paper, we attempt to prove empirically that a properly designed organization context can positively affect employee's perception of job embeddedness. Furthermore, employees' perception of embeddeness can lead to effective work team management. In the next section, we will review literature and propose a research model. Based on the research model, we derived three set of total twelve hypotheses. These hypotheses are tested through data collected from a national survey of 144 companies from the Taiwanese information service industry. Our finding indicates that the relationships among organization context, job embeddedness, and knowledge work team performance are more complicate then what the current literature described. The general correlation among the three concepts does exist. However, knowledge workers' autonomy, believed to be an important factor contributing to knowledge worker's productivity, does not have significant correlation with job embeddedness. Based on these findings, we explore possible explanations and identify future research directions.

\section{LITERATURE REVIEWS}

A work term can be defined as interdependent collections of individuals who share responsibility for specific outcomes for their organizations. Since managing work teams is of critical importance to all organizations, a variety of models have been proposed and explored to understand work team effectiveness from literature review (e.g., Janz et al., 1997; Kubo and Saka, 2002; Janz and Prasarnphanich, 2003).

However, all current frameworks explaining how to achieve the effectiveness of managing knowledge work teams (KWT) have not yet been convincingly validated (Trent, 2003). We have identified two areas for improvement in this paper. First, the management of knowledge workers is discussed largely within the context of Research \& Design (R\&D) or engineering teams (Doolen, et al., 2006). Most findings cannot be generalized to other contexts. A second gap in the team effectiveness literature is that most models discuss only direct relationship between work team dynamics and work team effectiveness, ignoring factors that may moderate this relationship. In particular, we identified that the knowledge workers' job embeddedness is one potential moderating factor being ignored. This factor is the main focus of our study.

Job embeddedness is now a well recognized human and social capital, which make up an organization's unique assets (e.g., Alvesson, 2001; Newell et al., 2001). The concept of Job embeddedness, proposed by Mitchell et al. (2001), is the strength of individuals' links to other people, team and groups. Mitchell et al. also suggest job embeddedness may associate with his/her intentions to stay or leave an organization. However, the concept of job embeddedness was defined generally in working teams of any kind. We suspect that the meaning of job embeddedness may change when it is used in a more dynamic environment with weaker tie amongst members, such as a knowledge worker team. In fact, Normann and Ramirez had already pointed out long ago that knowledge workers' job embeddedness requires further investigation (Normann and Ramirez, 1993). However, few literatures have tried to study knowledge worker's job embeddedness. The link between relational assets such as job embeddedness with team effectiveness is a relevant and important research topic, but has neglected by previous studies.

Moreover, since the effectiveness of managing KWT is dynamically interrelated with organizational context, the attributes of organization context are also of critical importance to the effectiveness of managing KWT. Differences in the attributes of organizational context can be associated with employees' job embeddedness and can have impacts on the effectiveness of managing KWT. Yet, few studies report empirical tests of the links between attributes of organizational context, employees' job embeddedness, and the effectiveness of managing KWT. We propose to study these relationships empirically.

\section{THE PROPOSED HYPOTHESES}

The main objective of this study is to establish the links between organizational context, job embeddedness and the effectiveness of managing KWT. A theoretical model is proposed and shown Figure 1. In this study, job embeddedness is considered as key moderating construct between knowledge workers and work team effectiveness. We believe that team-oriented work environment provides opportunities for employees to learn from those knowledgeable colleagues who are supportive and willing to help one another (Janz et al., 1997; Janz and Prasarnphanich, 2003). Swart and Kinnie (2003) state that sharing and integrating knowledge within the 
organization depends partly on building social capital. It is of interest to us to understand how the organizational context can help to foster job embeddedness. That is, the existence of certain contextual characteristics of the organization may facilitate and encourage knowledge workers' job embeddedness and in turn improve the effectiveness of managing KWT.

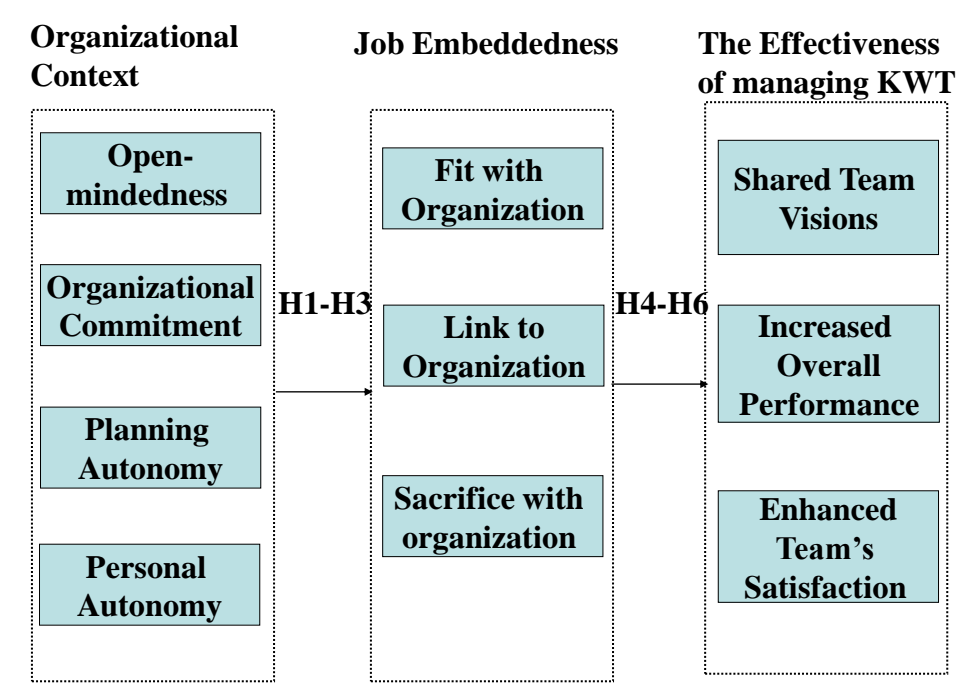

Figure 1 Research Model of Current Study

Four factors related to organizational context are considered: organizational open-mindedness, organizational commitment, planning autonomy and personnel autonomy. The first two constructs, organizational open-mindedness and organizational commitment, relates to the context of organizational learning (Chan, Lim and Keasberry, 2003). This study defines organizational open-mindedness as the extent of which organization encourages their employees' willingness to adapt to change. In contrast, organization commitment refers to the extent to which individuals feel loyal to their organization (Slattery and Selvarajan, 2005). Many desirable outcomes for both individuals and organizations have been associated with organizational open-mindedness and commitment. For example, knowledge sharing is more likely to happen in an organization with committed employees and openminded organization culture (Slattery and Selvarajan, 2005). This is especially true in a teamwork environment; team members are more willing to work together in a committed and open-minded organizational atmosphere (Trent, 2003).

The third and fourth constructs relate to job autonomies. Perceived autonomy may be the most critical concern in KWT. It has been verified that knowledge workers prefer autonomy more than any other job-related characteristic (e.g., Kubo and Saka, 2002; Drucker, 1999; Chency, 1984). An organization's ability to plan, structure, and support job autonomy largely determine the success and failure of KWT in the organization. Several forms of autonomy have been discussed in previous research (e.g., Darr, 2003; Janz and Prasarnphanich, 2003). In this study, we focus on autonomy over planning decisions and autonomy over personal task decisions, as these types of autonomy are characteristic of typical knowledge work activities (Jaze and Prasarnphanich, 2003). Autonomy and interdependence have been common leverage points for motivating teams, and are consequently included in most models of team effectiveness (e.g., Sundstrom et al., 1990; Janz et al., 1997).

Mitchell et al. (2001) label job embeddedness by means of three dimensions: link, fit and sacrifice. The three dimensions are important both on and off the job. Links are characterized as formal or informal connections between a person and institution or other people. Fit is defined an employee's perceived compatibility or perceived comfort with an organization and with his or her environment. Sacrifice captures the perceived cost of material or psychological benefit that may be forfeited to hold on to a job. 
This study predicts that the extent of organizational open-mindedness and organizational commitment, planning autonomy and personal autonomy will positively relate to the extent of employees' job embeddedness.

Hypothesis 1: The extent of knowledge workers' perceptions of (a) organizational open-mindedness, (b) organizational commitment, (c) planning autonomy, and (d) personal autonomy will positively relate to how they match with their works and companies.

Hypothesis 2: The extent of knowledge workers' perceptions of (a) organizational open-mindedness, (b) organizational commitment, (c) planning autonomy, and (d) personal autonomy will positively relate to how they link with their works and companies.

Hypothesis 3: The extent of knowledge workers' perceptions of (a) organizational open-mindedness, (b) organizational commitment, (c) planning autonomy, and (d) personal autonomy will positively relate to how they sacrifice with their works and companies.

Knowledge workers can become embedded in many ways; the process may systematically vary by occupation or personality. The critical aspects of job embeddedness are as follows:

1. the extent to which people have link to other people or activities,

2. the extent to which their job and communities are similar to or fit with the other aspects in their life spaces, and

3. the ease with which links can be broken-what they would give up if they left, especially if they had to physically move to other cities or homes.

In our research model, the effectiveness of KWT management is represented by three constructs. They are the shared visions, overall performance, and the satisfaction. Given that working together in groups or teams towards a shared goal is viewed as an important element of human existence. That is, when team has a vision, objectives can be set and the effectiveness of these objectives can be determined.

The higher extent of job embeddedness represents the employees' good relationship in their jobs. An increasing number of scholars (e.g., Burt et al., 2000; Tsai and Ghoshal, 1998) have employed the concept of social capital to their studies of relationship. Several scholars (e.g., Burt, 1992) have conceptualized social capital as a set of social resource embedded in relationships. To develop an inter-personal relationship implies that it invests its scarce resources and energy to develop and sustain a relationship with another person when the possible returns on this investment are often unpredictable or intangible. In turn, social networks can facilitate access to information, resources, and opportunities, to coordinate critical task interdependencies, and overcome the dilemmas of cooperation and collective action (Burt, 1992, Gargiulo and Benassi, 2000), to promote a normative environment that facilitate trust and cooperation between actors (Coleman, 1990). Accordingly, good connections are of valuable for the effectiveness of managing KWT. For example, researchers (e.g., West, 2001, Burch and Anderson, 2004) state that if the team is to be effective, it will need to be driven forward by either an implicit or explicit shared vision. Thus, this study proposes shared vision is valued as one of the outcomes of managing KWT and can be developed from within the KWT. Therefore, this study proposes that job embeddedness will positively related to shared visions, overall performance, and the satisfaction of KWT.

Hypothesis 4: The extent of knowledge workers' perceptions of (a) how they match with (b) how they link with (c) how they sacrifice with their works and companies will positively relate to the shared visions of KWT.

Hypothesis 5: The extent of knowledge workers' perceptions of (a) how they match with (b) how they link with (c) how they sacrifice with their works and companies will positively relate to the overall performance of KWT.

Hypothesis 6: The extent of knowledge workers' perceptions of(a) how they match with (b) how they link with (c) how they sacrifice with their works and companies will positively relate to the satisfaction of KWT. 


\section{RESEARCH METHOD}

To test the proposed hypothesis empirically, this study selected knowledge workers from software companies in Taiwan as our target population. This particular audience was chosen as these firms are knowledge intensive. To identify knowledge workers' teams for the sample, teams from information systems departments will ideal for study because they represent an exemplar of knowledge workers (Janz et al., 1997; Bartol and Martin, 1982). This study used a seven-point Likert scale to ensure statistical variability among survey responses for all constructs. The survey instrument was pilot tested by 36 EMBA students studying at two universities in Taiwan. The Cronbach's $\alpha$ values of the pilot test for the all constructs are all above 0.7 , suggesting that the instrument is reliable. A list with 1150 member corporations' full names, addresses, and corresponding managers was collected. The variables of selected constructs were operationalized in the form of a questionnaire. Of the 1150 surveys mailed, we received 144 usable responses, which represent a $12.52 \%$ response rate.

\section{DATA ANALYSIS AND RESULTS}

This section presents the analysis results. First, the nature of the data is explored. Second, factor analysis is employed to confirm the dimensionality of proposal constructs. Third, the hypotheses are tested using SPSS10.1. For the sample characteristics, the average age of respondents was 29.8 years; 80.7 percent earned their degree from undergraduate and postgraduate; 67.4 percent were male and 32.6 were female. They had worked in their current work teams for an average 4.47 years, for the work teams for an average 6.4 years, and the average members of work teams were 16.2 persons.

In this study, factor analysis and a multivariate regression model is used to test the reliability and validity of constructs and hypothesized relationships. Factor analysis is a multivariate statistical technique that is concerned with defining new factor variates as linear transformations of original correlated variables. This study conducted a principal components factor analysis with VARIMAX rotation to assess convergence within and divergence between scales. Items composing the various power scales are factor analyzed to assess their convergent and discriminant validity. Appendix 1 presents the means, standard deviations, and correlations of the proposed constructs. According to Hair et al. [35], a commonly used threshold value for acceptable reliability is 0.70 . As shown in appendix 1, cronbach's $\alpha$ values for the all constructs, which have three or more indicators range from 0.7306 to 0.9053 , suggesting that the instrument is reliable. Table 1 shows the means, S.D. and inter-correlations among constructs.

Table 1. Mean, S.D. and Inter-correlations among Constructs

\begin{tabular}{|c|c|c|c|c|c|c|c|c|c|c|c|}
\hline Constructs & Mean & S.D. & (1) & (2) & (3) & (4) & (5) & (6) & (7) & (8) & (9) \\
\hline 1. Fit with organization & 5.5545 & 0.875 & & & & & & & & & \\
\hline 2. Link with organization. & 5.590 & 0.935 & 0.519 & & & & & & & & \\
\hline 3.Sacrifice with organization & 4.849 & 1.084 & 0.396 & 0.445 & & & & & & & \\
\hline 4. Shared team vision & 4.998 & 1.006 & 0.402 & 0.391 & 0.557 & & & & & & \\
\hline 5. Team performance & 5.010 & 0.966 & 0.547 & 0.424 & 0.456 & 0.537 & & & & & \\
\hline 6. Team satisfaction & 5.465 & 0.838 & 0.661 & 0.505 & 0.559 & 0.549 & 0.662 & & & & \\
\hline 7. Open mindedness & 5.010 & 1.133 & 0.548 & 0.397 & 0.546 & 0.683 & 0.445 & 0.555 & & & \\
\hline 8. Autonomy of plan & 5.312 & 0.881 & 0.511 & 0.592 & 0.386 & 0.252 & 0.315 & 0.463 & 0.309 & & \\
\hline 9. Organizational commitment & 6.113 & 0.741 & 0.515 & 0.365 & 0.413 & 0.362 & 0.359 & 0.462 & 0.468 & 0.340 & \\
\hline 10. Autonomy of people & 4.761 & 1.083 & 0.286 & 0.339 & 0.366 & 0.328 & 0.103 & 0.386 & 0.374 & 0.467 & 0.280 \\
\hline
\end{tabular}

After establishing items loaded appropriately on their expected constructs, the hypotheses were tested by using linear regression models. Accordingly, based on the proposed theoretical model, this step involves building the following six regression equations:

Model 1: Fit with organization $=\beta_{0}+\beta_{1}($ Open-mindedness $)+\beta_{2}($ Org. Commitment $)+\beta_{3}($ Planning autonomy $)+$ $\beta_{4}$ (Personnel autonomy) $+\mu$

Model 2: Link with organization $=\beta_{0}+\beta_{1}$ (Open-mindedness $)+\beta_{2}($ Org. Commitment $)+\beta_{3}$ (Planning autonomy $)+$ $\beta_{4}$ (Personnel autonomy) $+\mu$ 
Model 3: Sacrifice with organization $=\beta_{0}+\beta_{1}($ Open-mindedness $)+\beta_{2}($ Org. Commitment $)+\beta_{3}($ Planning autonomy $)$ $+\beta_{4}$ (Personnel autonomy) $+\mu$

Model 4: Shared vision $=\beta_{0}+\beta_{1}$ (Fit with organization $)+\beta_{2}$ (Link with organization) $+\beta_{3}$ (Sacrifice with organization $)+\mu$

Model 5: Overall performance $=\beta_{0}+\beta_{1}$ (Fit with organization $)+\beta_{2}($ Link with organization $)+\beta 3$ (Sacrifice with organization $)+\mu$

Model 6: Satisfaction $=\beta 0+\beta_{1}$ (Fit with organization $)+\beta_{2}($ Link with organization $)+\beta_{3}$ (Sacrifice with organization $)+\mu$

Table 2 shows the results of linear regressions of model 1-3. The F statistics of model 1 ( $F=32.054$, Sign. of $\mathrm{F}=.000)$, model 2(F=25.054, Sign. of $\mathrm{F}=.000)$, and $3(\mathrm{~F}=27.788$, Sign. of $\mathrm{F}=.000)$ suggest that these three regression models are statistically significant. As shown in Table 3, the F statistics of model 4 ( $F=25.821$, Sign. of $F=.000)$, model $5(\mathrm{~F}=27.978$, Sign. of $\mathrm{F}=.000)$, and $6(\mathrm{~F}=57.217$, Sign. of $\mathrm{F}=.000)$ suggest that models 4 to model 6 are also statistically significant. Table 2 and Table 3 also exhibit the path coefficient and t-value of each hypothesized path. Path estimations which have t-value greater than 1.96 can be considered to be significant, based on the level of $\alpha=0.05$.

Table 2: The regression models of H1-H3

\begin{tabular}{lccc}
\hline & $\begin{array}{c}\text { Fit wit org. } \\
\text { (model 1) }\end{array}$ & $\begin{array}{c}\text { Link with org. } \\
\text { (model 2) }\end{array}$ & $\begin{array}{c}\text { Sacrifice with org. } \\
\text { (model 3) }\end{array}$ \\
\hline & $\beta / \mathrm{T}(\mathrm{P})$ & $\beta / \mathrm{T}(\mathrm{P})$ & $\beta / \mathrm{T}(\mathrm{P})$ \\
Open-mindedness & $.350 / 4.831(.000)$ & $.192 / 2.484(.035)$ & $.387 / 4.877(.000)$ \\
Org. commitment & $.354 / 4.951(.000)$ & $.493 / 6.462(.014)$ & $.169 / 2.155(.033)$ \\
Planning autonomy & $.254 / 3.563(.001)$ & $.106 / 1.398(.164)$ & $.146 / 1.875(.063)$ \\
Personnel autonomy & $-.082 /-1.135(.258)$ & $.007 / 0.097(.923)$ & $.101 / 1.279(.203)$ \\
\hline $\mathrm{R}^{2}$ (Adj. R ${ }^{2}$ ) & $0.480(0.465)$ & $0.409(0.392)$ & $0.3741(0.356)$ \\
F (Sign. Of F) & $32.054(0.000)$ & $24.054(0.000)$ & $20.788(0.000)$ \\
DF & 4,139 & 4,139 & 4,139 \\
\hline
\end{tabular}

Table 3: The regression models of H4-H6

\begin{tabular}{lccc}
\hline & $\begin{array}{c}\text { Shared vision } \\
\text { (model 4) }\end{array}$ & $\begin{array}{c}\text { Overall performance } \\
\text { (model 5) }\end{array}$ & $\begin{array}{c}\text { Satisfaction } \\
\text { (model 6) }\end{array}$ \\
\hline & $\beta / \mathrm{T}(\mathrm{P})$ & $\beta / \mathrm{T}(\mathrm{P})$ & $\beta / \mathrm{T}(\mathrm{P})$ \\
Fit with Org. & $.172 / 2.120(.036)$ & $.390 / 4.870(.000)$ & $.474 / 6.982(.000)$ \\
Link with Org. & $.105 / 1.265(.208)$ & $.109 / 1.326(.187)$ & $.118 / 1.689(.093)$ \\
Sacrifice with Org. & $.442 / 5.649(.000)$ & $.253 / 3.315(.001)$ & $.319 / 4.922(.000)$ \\
\hline $\mathrm{R}^{2}$ (Adj. $\left.\mathrm{R}^{2}\right)$ & $0.356(0.342)$ & $0.375(0.361)$ & $0.551(0.541)$ \\
$\mathrm{F}$ (Sign. Of F) & $25.821(0.000)$ & $27.978(0.000)$ & $57.217(0.000)$ \\
$\mathrm{DF}$ & 3,140 & 3,140 & 3,140 \\
\hline
\end{tabular}

As expected and shown in model 1 , fit wit organization was positively related to open-mindedness $(b=$ $0.350, \mathrm{t}=4.831, \mathrm{p}<0.01)$, organizational commitment $(\mathrm{b}=0.354, \mathrm{t}=4.951, \mathrm{p}<0.01)$, and planning autonomy $(\mathrm{b}=$ $0.254, \mathrm{t}=3.563, \mathrm{p}=0.01$ ). Therefore, hypotheses $\mathrm{H} 1 \mathrm{a}, \mathrm{H} 1 \mathrm{~b}$, and $\mathrm{H} 1 \mathrm{c}$ are supported. The results did not support the relationships between fit wit organization and personnel autonomy $(b=-0.082, t=-1.135, p>0.05)$. Therefore, the hypothesis H1d is not supported. As shown in model 2, consistent with expectations, link with organization was positively related to open-mindedness $(b=0.192, t=2.484, p<0.05)$ and, organizational commitment $(b=0.493, t=$ $6.462, \mathrm{p}<0.05$ ); thus $\mathrm{H} 2 \mathrm{a}$ and $\mathrm{H} 2 \mathrm{~b}$ are supported. However, the results did not support the relationships between global mindset and planning autonomy $(b=0.106, t=1.398, p>0.05)$ and personnel autonomy $(b=0.007, t=0.097$, $\mathrm{p}>0.05)$. The hypotheses $\mathrm{H} 2 \mathrm{c}$ and $\mathrm{H} 2 \mathrm{~d}$ are not supported. In model 3 , the effects of open-mindedness $(\mathrm{b}=0.387, \mathrm{t}=$ 4.877, $\mathrm{p}<0.01)$, and organizational commitment $(\mathrm{b}=0.169, \mathrm{t}=2.155, \mathrm{p}<0.05)$ on the sacrifice with organization were significant; thus $\mathrm{H} 3 \mathrm{a}$ and $\mathrm{H} 3 \mathrm{~b}$ are supported. But, the effects of planning autonomy $(b=0.146, t=1.775$, $\mathrm{p}>0.05)$, and personnel autonomy $(b=0.101, t=1.279, p>0.05)$ on the sacrifice with organization were not significant. Therefore, thus $\mathrm{H} 3 \mathrm{c}$ and $\mathrm{H} 3 \mathrm{~d}$ are supported. 
In model 4 , the results did not support the relationships between shared vision and link with organization (b $=0.105, \mathrm{t}=1.265, \mathrm{p}>0.05)$. The hypotheses $\mathrm{H} 4 \mathrm{~b}$ are not supported. As was expected, share vision was positively related to link with organization $(b=0.172, t=2.120, p<0.05)$ and sacrifice with organization $(b=0.442, t=5.649$, $\mathrm{p}<0.01$ ). Therefore, hypotheses $\mathrm{H} 4 \mathrm{a}$ and $\mathrm{H} 4 \mathrm{c}$ are supported. It was predicted that fit with organization, link with organization and sacrifice with organization would have positive effects on the overall performance (H5a, H5b and H5c). The effects of fit with organization $(b=0.390, t=4.870, p<0.01)$ and sacrifice with organization $(b=0.253, t$ $=3.325, \mathrm{p}<0.05)$ on the overall performance were significant. H5a and H5c are supported. Since link with organization $(b=0.109, t=1.329, p>0.05)$ has no significant effect on the overall performance, H5b is not supported. Similar to model 4 and model 5 , model 6 shows only fit with organization $(b=0.474, t=6.982, p<0.01)$ and sacrifice with organization $(b=0.319, t=4.922, p<0.05)$ have significant effects on the satisfaction, but not link with organization $(b=0.118, t=1.689, p>0.05)$. Therefore, H6a and H6c are supported and H6b is not supported.

\section{FINDINGS AND IMPLICATIONS}

Table 4 summarizes our findings. Thirteen of the twenty-one hypothesized link are supported by the empirical data.

Table 4: Summaries of hypotheses testing

\begin{tabular}{|c|c|c|c|c|}
\hline Hypothesis & Hypothesized Path & Std. $\beta$ & $\begin{array}{c}\mathrm{t}- \\
\text { values }\end{array}$ & $\begin{array}{c}\text { Hypothesis } \\
\text { Support }\end{array}$ \\
\hline H1a & Open-mindedness $\rightarrow$ Fit wit org. & $.350 * *$ & 4.831 & Yes \\
\hline $\mathrm{H} 1 \mathrm{~b}$ & Org. commitment $\rightarrow$ Fit wit org. & $.354 * *$ & 4.951 & Yes \\
\hline $\mathrm{H} 1 \mathrm{c}$ & Planning autonomy $\rightarrow$ Fit wit org. & $.254 * *$ & 3.563 & Yes \\
\hline H1d & Personal autonomy $\rightarrow$ Fit wit org. & -.082 & -1.135 & No \\
\hline $\mathrm{H} 2 \mathrm{a}$ & Open-mindedness $\rightarrow$ Link with org. & $.192 *$ & 2.484 & Yes \\
\hline $\mathrm{H} 2 \mathrm{~b}$ & Org. commitment $\rightarrow$ Link with org. & $.493 *$ & 6.462 & Yes \\
\hline $\mathrm{H} 2 \mathrm{c}$ & Planning autonomy $\rightarrow$ Link with org. & .106 & 1.398 & No \\
\hline $\mathrm{H} 2 \mathrm{~d}$ & Personal autonomy $\rightarrow$ Link with org. & .007 & 0.097 & No \\
\hline $\mathrm{H} 3 \mathrm{a}$ & Open-mindedness $\rightarrow$ Sacrifice with org. & $.387 * *$ & 4.877 & Yes \\
\hline $\mathrm{H} 3 \mathrm{~b}$ & Org. commitment $\rightarrow$ Sacrifice with org. & $.169 *$ & 2.155 & Yes \\
\hline $\mathrm{H} 3 \mathrm{c}$ & Planning autonomy $\rightarrow$ Sacrifice with org. & .146 & 1.875 & No \\
\hline $\mathrm{H} 3 \mathrm{~d}$ & Personal autonomy $\rightarrow$ Sacrifice with org. & .101 & 1.279 & No \\
\hline $\mathrm{H} 4 \mathrm{a}$ & Fit with Org. $\rightarrow$ Shared vision & $.172 *$ & 2.120 & Yes \\
\hline $\mathrm{H} 4 \mathrm{~b}$ & Link with org. $\rightarrow$ Shared vision & .105 & 1.265 & No \\
\hline $\mathrm{H} 4 \mathrm{c}$ & Sacrifice with org. $\rightarrow$ Shared vision & $.442 * *$ & 5.649 & Yes \\
\hline H5a & Fit with Org $\rightarrow$ Overall performance & $.390 * *$ & 4.870 & Yes \\
\hline $\mathrm{H} 5 \mathrm{~b}$ & Link with org. $\rightarrow$ Overall performance & .109 & 1.326 & No \\
\hline $\mathrm{H} 5 \mathrm{c}$ & Sacrifice with org. $\rightarrow$ Overall performance & $.253 * *$ & 3.315 & Yes \\
\hline H6a & Fit with Org. $\rightarrow$ Satisfaction & $.474 * *$ & 6.982 & Yes \\
\hline $\mathrm{H} 6 \mathrm{~b}$ & Link with org. $\rightarrow$ Satisfaction & .118 & 1.689 & No \\
\hline $\mathrm{H} 6 \mathrm{c}$ & Sacrifice with org. $\rightarrow$ Satisfaction & $.319 * *$ & 4.922 & Yes \\
\hline
\end{tabular}

The results of this study offer many practical implications for design of team-based knowledge work, especially where managers can accurately identify and diagnose relevant process and contextual factors. Our results suggest that organizational context including organizational open-mindedness and organizational commitment have positive effect on knowledge workers' job embeddedness. This result may suggest that team researchers should continue to study how the context characteristics can be created in team-based context.

However, knowledge workers' job autonomies, planning autonomy and personal autonomy, do not have positive effect on job embeddedness. This study finds that the information service industries which work centered on information tasks and services had been expanding greatly when compared to other more mechanical functions. Individuals are assigned to projects based on their expertise and are expected to help one another by sharing knowledge freely. The mind-set of a typical team member is that members should care about the success of the projects instead of their personal contribution, as their work environments are reinforced by an incentive system that 
emphasizes the overall performance of the KWT. Probably, this is the reason why that job autonomies do not show positive effect on job embeddedness. Also, this phenomenon may be specific to the IT industry in Taiwan.

Current research on work teams in organizational contexts stems from the development of psycho-social theory and inquiry in the filed of group psychology (Gil et al., 2005). Accordingly, further study should focus on (1) the integration of factors from macro level (organizational factors) with micro level (psychological factors), and (2) the examination the impacts of the interaction between macro and micro level on the effectiveness of KWT. Also, from a statistical perspective, the causal relationships are still not clear enough. Further research may employ the more powerful methods such as structural equation modeling to explore the causal relationships clearly.

Furthermore, the reawakening of interest in work teams is related with wider changes in the world of work and organizations driven by economic, strategic and technological imperatives. Especially, the pressures of global competition, it is interesting to note that organizations have to pay much more attentions to examine the effects of diversity on team performance under a variety of circumstances.

\section{AUTHOR INFORMATION}

Jau-Rong Chen is an Associate Professor of the Business Management Department at Ming Chi University of Technology, Taiwan, R.O.C. She received her Ph.D. in Training and Human Resources Development from University of Warwick, UK in 2002. Dr. Chen's research focuses on four main areas: IT outsourcing management, continuing professional development, organizational learning, and cross-cultural learning. Currently she is extending her research in continuing professional development to focus on the issue of conflict management from social theories perspectives.

Tzu-Chuan Chou is an Associate Professor, Department of the Information Management at National Taiwan University of Science and Technology, Taiwan. He received his Ph.D. from Warwick Business School, the University of Warwick, UK in 1999. Dr. Chou's research focuses on IT management, knowledge management, organizational behaviour, and strategy management. His articles have appeared in the Decision Support Systems, Management Decision, Information and Management, International Journal Information Management, OMEGA and among others.

Te-Wei Wang is a cross disciplinary researcher in the areas of information systems and production operation management. He is currently an assistant professor at University of Illinois Springfield. His research interests include knowledge management, e-commerce assurance service, information systems analysis and design, requirement engineering and enterprise resource planning. His work shows up on Journals such as Journal of Database Management, Decision Support Systems and many national and international conferences.

\section{REFERENCES}

1. Anderson, N., and Ostroff, C. (1997). "Selection as socialization". In N. Anderson and P. Herriot (Eds.), International handbook of selection and assessment (pp. 413-440). Chichester: Wiley.

2. Bartol, K. M. and Marin, D. C. (1982). "Managing Information Systems Personnel: A Review of the Literature and Managerial Implications". MIS Quarterly Special Issue, pp. 49-70.

3. Burch, G..St.J., and Anderson, N. (2004). "Measuring person-team fit: Development and validation of the team selection inventory." Journal of Managerial Psychology, 19 (4), 406-426.

4. Darr, A. (2003). "Control and Autonomy Among Knowledge Workers in Sales: An Employee Perspective". Employee Relations, 225(1/2), 31-41.

5. Dineen, B. R. (2005), "TeamXchange: A Team Project Experience Involving Virtual Teams and Fluid Team Membership", Journal of Management Education, 29(4), 595-616.

6. Doolen, T. L. Hacker, M. E. and Van Aken, E. (2006), "Managing Organizational Context for Engineering Team Effectiveness", Team Performance Management, 12(5/6), 138-154.

7. Drucker, P. F. (1999). "Knowledge-Worker Productivity: The Biggest Challenge". California Management Review, 41 (2), 79-94. 
8. Erden, F. and Ozen, J. (2003). "Cognitive and Effective Dimensions of Trust in Developing team Performance". Team Performance Management, 9(5/6), 131-135.

9. Gil, F. Alcover, C.-M., and Peiro, J.-M. (2005). "Work Team Effectiveness in Organizational Contexts: Recent Research and Applications in Spain and Portugal". Journal of Managerial Psychology, 20(3/4), 193-218.

10. Guzzo, R. A. and Dickson, M. W. (1996). “Teams in Organizations: Recent Research on Performance and Effectiveness". Annual Review of Psychology, 47, 307-338.

11. Hackman, J. R. (1987). “The design of work teams”. In Handbook of Organizational Behavior, Ch. 20 (pp. 315-342). Prentice Hall, Englewood Cliffs, NJ.

12. Janz, B. D., Colquitt, J. A. and Noe, R. A. (1997). "Knowledge Workers Team Effectiveness: The Role of Autonomy, Interdependence, Team Development, and Contextual Support Variables". Personnel Psychology, 50 (4), 877-904.

13. Jazn, B. D. and Prasarnphanich, P. (2003). "Understanding the Antecedents of Effective Knowledge Management: The Importance of a Knowledge-Centered Culture”. Decision Sciences, 34(2), 351-384.

14. Kubo, I. and Saka, A. (2002). "An Inquiry into the Motivations of Knowledge Workers in Japanese Financial Industry”. Journal of Knowledge Management, 6(3), 262-271.

15. Iyer, B. and Davenport, T. H. (2008). "Reverse Engineering Google's Innovation Machine." Harvard Business Review, ?(?).

16. Mitchell, T. R., Holtom, B. C., Lee, T. W. Sablynski, C. J., and Dre, M. (2001). "Why People Stay: Using Job Embeddedness to Predict Voluntary Turnover”. Academy of Management Journal, 44(6), 1102-1121.

17. Normann R and Ramirez R (1993). "From Value Chain to Value Constellation: Designing Interactive strategy." Harvard Business Review, 71 (4) 65-78.

18. Poundstone, W. (2003). How would you move mount Fuji? Microsoft's Cult of Puzzle, How the World's martest company select the most creative thinkers. Little Brown and Compnay, New York.

19. Safferston, M. J. (1998), "Book Review, The Distributed Mind: Achieving High Performance Through the Collective Intelligence of Knowledge Work Teams.” The Academy of Management Executive, 12 (2), 107108 .

20. Scarbrough, H. (1999). "Knowledge as Work: Conflicts in the Management of Knowledge Workers". Technology Analysis \& Strategic Management, 11(1), 5-16.

21. Trent, R. J. (2003). "Planning to use work teams effectively". Team Performance Management, 9(3/4), 5058.

22. West, MA (2001). “The Human Team: Basic Motivations and Innovations”. In N. Anderson, DS Ones, HK. Sinangil, and C. Viswesvaran (Eds.), Handbook of industrial, work and organizational psychology (Vol. 2, pp. 270-288). London/New York: Sage.

23. West, M. A., and Markiewicz, L. (2004), Building Team-Based Working: A Practical Guide to Organizational Transformation, Oxford: Blackwell. 


\section{NOTES}

